\title{
Fit of the 2011 Indonesian Mortality Table to Gompertz's and Makeham's Law using Maximum Likelihood Estimation
}

\author{
Dino Agustin Putra, Nina Fitriyati, and Mahmudi \\ Mathematics Department, Science and Technology Faculty, UIN Sultan Syarif Kasim Riau \\ Jl. HR. Soebrantas No. 155 Simpang Baru, Panam, Pekanbaru, 28293 \\ Email: dino.agustin15@mhs.uinjkt.ac.id, \{nina.fitriyati,mahmudi\}@uinjkt.ac.id
}

\begin{abstract}
This research discusses the estimation of the parameters for Gompertz's law and Makeham's law using the Maximum Likelihood Estimation method. A numerical approach to estimate the parameters of Gompertz's law is the Newton-Raphson method. In the Makeham's law, we use the Lagrange multiplier method to solve constraints of $0.001<A<0.003,10^{-6}<B<10^{-3}$, and $1.075<C<1.115$, and Broyden as a method to estimate the parameter numerically. The estimation result shows that parameter $B$ converges to 0.005749 and parameter $C$ converges to 1.024738 in the Gompertz's law. In the Makeham's law, the estimated parameters that satisfied the constraints are $A$ converges to 0.00300344 , $B$ converges to 0.0002716465 , and $C$ converges to 1.113395 . Based on the Average Relative Error (ARE) that calculated from the estimated for $p_{x}$, the 2011 Indonesian Mortality Table (the 2011 TMI) for men and for women are more accurate when approached using the Gompertz's law than the Makeham's law. The estimated for $p_{x}$ uses the Gompertz's law are very close to the $p_{x}$ at the 2011 TMI (with Absolute Percentage Errors of less than 1\%) at age intervals, for men: $0-10$ years, $10-20$ years, $20-30$ years, and $60-70$ years, and for women: $0-10$ years, $10-20$ years, and $70-80$ years.
\end{abstract}

Keywords: parameter estimation; Newton-Raphson method; Broyden method; Lagrange Multiplier method.

\begin{abstract}
Abstrak
Penelitian ini membahas mengenai estimasi parameter hukum mortalitas Gompertz's dan hukum mortalitas Makeham's menggunakan metode Maximum Likelihood Estimation. Pendekatan numerik untuk estimasi parameter hukum mortalitas Gompertz dilakukan menggunakan metode Newton-Raphson. Untuk mengatasi syarat batas $0,001<A<0,003,10^{-6}<B<10^{-3}$, dan $1,1075<C<1,115$, pada estimasi parameter hukum mortalita Makeham digunakan metode pengali Lagrange dan pendekatan numerik metode Broyden. Hasil estimasi menunjukkan bahwa parameter $B$ konvergen ke 0,005749 dan parameter $C$ konvergen ke 1,024738 pada hukum mortalitas Gompertz. Pada hukum mortalitas Makeham's, hasil estimasi parameter yang memenuhi syarat batas adalah nilai $A$ konvergen ke 0,00300344, $B$ konvergen ke 0,0002716465, dan $C$ konvergen ke 1,113395. Berdasarkan nilai Average Relative Error (ARE) yang dihitung untuk estimasi $p_{x}$, Tabel Mortalita Indonesia (TMI 2011) untuk pria dan untuk wanita lebih sesuai jika didekati menggunakan hukum Gompertz daripada hukum Makeham. Estimasi $p_{x}$ menggunakan pendekatan hukum Gompertz berada sangat dekat dengan nilai $p_{x}$ pada TMI 2011 (dengan Mean Absolute Percentage Error kurang dari 1\%) pada interval usia, untuk pria:
\end{abstract}


Fit of the 2011 Indonesian Mortality Table 2011 to Gompertz's and Makeham's Law using Maximum...

$0-10$ tahun, $10-20$ tahun, $20-30$ tahun, dan $60-70$ tahun, dan untuk wanita: $0-10$ tahun, $10-20$

tahun, dan 70 - 80 tahun.

Kata estimasi parameter; metode Newton-Raphson; metode Broyden; metode Pengali Lagrange.

\section{INTRODUCTION}

Gompertz's mortality law was proposed by Benjamin Gompertz in 1825. This model is often used in survival analysis. Gompertz's Mortality Law is used to determine someone's probability of life and death by defining the force of mortality as [1]:

$$
\mu(x)=B C^{x}, B>0, C>1, x \geq 0,
$$

probability density function (pdf) as

$$
f(x)=B C^{x} \cdot \exp \left[\frac{-B}{\ln C}\left(C^{x}-1\right)\right],
$$

and the probability function of someone $x$ years old will stay alive until $x+t$ years old is expressed by:

$$
{ }_{t} p_{x}=\exp \left(-\frac{B C^{x}}{\ln C}\left(C^{t}-1\right)\right)
$$

Not only for insurance but Gompertz's law also used to demography research [2] and biology [3].

Mortality tables can be approached using Gompertz's model [4]. William M. Makeham's (1980) conducted experiments on three mortality tables using the Gompertz's law. Makeham's stated that Gompertz's law needed to be modified so he developed Makeham's law [5] with the force of Mortality as:

$$
\mu(x)=A+B C^{x}, B>0, A>-B, C>1, x \geq 0,
$$

probability density function (pdf):

$$
f(x)=\left(A+B C^{x}\right) \cdot \exp \left[-\left(A x+\frac{B}{\ln C}\left(C^{x}-1\right)\right)\right]
$$

and the probability function of someone $x$ years old will stay alive until $x+t$ years old is expressed by:

$$
{ }_{t} p_{x}=\exp \left(-A t-\frac{B C^{x}}{\ln C}\left(C^{t}-1\right)\right)
$$

Based on [6], the interval of the parameter in Makeham's law are

$$
\begin{aligned}
& 0.001<A<0.003 \\
& 10^{-6}<B<10^{-3} \\
& 1.08<C<1.12
\end{aligned}
$$

Gompertz's Law calculates risk based on age, whereas Makeham's law calculates risk based on age and other factors that are not affected by age [7]. In the Gompertz's law, there are two parameters to be estimated, while in the Makeham's law, there are three parameters to be estimated. Several methods have been developed to estimate parameters in the Gompertz's law i.e. Ordinary Least Squares (OLS), Weighted Ordinary Least Squares (WOLS), Non-Linear Least Squares (NLLS), Weighted Non-Linear Least Squares (WNLLS) [8] and the Maximum Likelihood Estimation (MLE) 
method [9]. According to [10], the Maximum Likelihood Estimation method is more accurate in estimating the parameters of Gompertz's law than the Moment method. Whereas parameter estimation for Makeham's mortality law is more effective using the Least Squares (LS) than Maximum Likelihood Estimation (MLE). Some cases in the Makeham's mortality law contain the equation $\sum_{i=1}^{r} \frac{1}{A+B C^{x_{i}}}, \sum_{i=1}^{r} \frac{x_{i} B C^{x_{i}}}{A+B C^{x_{i}}}$ and so on which makes the estimation process more complex [11].

The difference in parameter estimation will affect the accuracy of the actuarial function. Before calculating the accuracy of an actuarial function, the fit of the death law with the death table must be considered. In 2012, Huang and Kristiani [12] examined the fit of Gompertz's law with the 2011 TMI using the Linear Least Square method. The results of this study indicate that the 2011 TMI for men is more appropriate to the Gompertz's law while the 2011 TMI for women is more appropriate to Makeham's law.

Inspired by Huang and Kristian [12], this article will discuss the suitability of Gompertz's law and Makeham's law to the 2011 TMI for men and women where the parameter will be estimated using the Maximum Likelihood Estimation. We use the Newton-Raphson method to estimate the parameter of Gompertz's law numerically. In the previous research, we used the Newton-Raphson method to estimate the parameter of Makeham's law numerically but this method didn't work well because of the Jacobian matrix in the Newton-Raphson formula does not have an inverse. Therefore, we use the Broyden method to estimate the parameter of Makeham's law numerically. The goodness of fit of the 2011 TMI will assess using the Average Relative Error (ARE) value.

\section{METHOD}

Let $X_{1}, X_{2}, \ldots, X_{n}$ be random sample size $n$ from a distribution that have pdf of Gompertz's law (equation (2)) or Makeham's law (equation (5)) with parameter $\theta \in \Omega$ where $\Omega$ is parameter space. The joint pdf of these random samples is [13]

$$
f\left(x_{1}, x_{2}, \ldots, x_{n} ; \theta\right)=f\left(x_{1} ; \theta\right) f\left(x_{2} ; \theta\right) \ldots f\left(x_{n} ; \theta\right)
$$

The likelihood and the log likelihood function for the Gompertz's law, respectively, are

$$
L(B, C)=\prod_{i=1}^{n} B C^{x_{i}} \cdot \exp \left[\frac{-B}{\ln C}\left(C^{x_{i}}-1\right)\right]
$$

and

$$
\ln (L(B, C))=n \cdot \ln B+\left(\sum_{i=1}^{n} x_{i}\right) \ln C-\frac{B}{\ln C} \sum_{i=1}^{n}\left(C^{x_{i}}-1\right) .
$$

The maximum estimation of parameter $B$ and $C$ will be obtained from the first differentiation of equation (10):

$$
\begin{gathered}
\frac{\partial \ln (L(B, C))}{\partial B}=\frac{n}{B}-\frac{1}{\ln C} \sum_{i=1}^{n}\left(C^{x_{i}}-1\right)=0 \\
\frac{\partial \ln (L(B, C))}{\partial C}=\frac{1}{C} \sum_{i=1}^{n} x_{i}+\frac{B}{C \ln ^{2} C} \sum_{i=1}^{n}\left(C^{x_{i}}-1\right)-\frac{B}{C \ln C} \sum_{i=1}^{n} x_{i} C^{x_{i}}=0
\end{gathered}
$$

In the Makeham's law, there are three tiga parameter i.e. $A, B$ and $C$ with three constraints i.e. $B>0, C>1$, and $A>-B$. To handle these constraints, we will combine the maximum likelihood estimation and Lagrange Multiplier method. The Lagrange Multiplier equation from the log of likelihood function is 
Fit of the 2011 Indonesian Mortality Table 2011 to Gompertz's and Makeham’s Law using Maximum...

$$
\begin{aligned}
\ln (L(A, B, C)) & =\sum_{i=1}^{n} \ln \left(\left(A+B C^{x_{i}}\right) \cdot \exp \left[-\left(A x_{i}+\frac{B}{\ln C}\left(C^{x_{i}}-1\right)\right)\right]\right)+\lambda_{1}(A+B)+\lambda_{2} B+\lambda_{3}(C-1) \\
& =\sum_{i=1}^{n} \ln \left(A+B C^{x_{i}}\right)-A \sum_{i=1}^{n} x_{i}-\frac{B}{\ln C} \sum_{i=1}^{n}\left(C^{x_{i}}-1\right)+\lambda_{1}(A+B)+\lambda_{2} B+\lambda_{3}(C-1) .
\end{aligned}
$$

Where $\lambda_{1}, \lambda_{2}$, and $\lambda_{3}$ are the Lagrange variables that can be find by the first partial derivative equation (13) respect to $A, B$ and $C$ and we get:

$$
\begin{gathered}
\lambda_{1}=\sum_{i=1}^{n} x_{i}-\sum_{i=1}^{n} \frac{1}{A+B C^{x_{i}}} \\
\lambda_{2}=\frac{1}{\ln C} \sum_{i=1}^{n}\left(C^{x_{i}}-1\right)-\sum_{i=1}^{n} x_{i}-\sum_{i=1}^{n} \frac{C^{x_{i}-1}}{A+B C^{x_{i}}}, \\
\lambda_{3}=\frac{B}{C \ln C} \sum_{i=1}^{n} x_{i} C^{x_{i}}-\sum_{i=1}^{n} \frac{B x_{i} C^{x_{i}-1}}{A+B C^{x_{i}}}-\frac{B}{C \ln ^{2} C} \sum_{i=1}^{n}\left(C^{x_{i}}-1\right) .
\end{gathered}
$$

Then equation (13) be

$$
\begin{aligned}
\ln (L(A, B, C))= & \sum_{i=1}^{n} \ln \left(A+B C^{x_{i}}\right)-A \sum_{i=1}^{n} \frac{1}{A+B C^{x_{i}}}-B \sum_{i=1}^{n} \frac{C^{x_{i}}}{A+B C^{x_{i}}}+\frac{B(C-1)}{C \ln C} \sum_{i=1}^{n} x_{i} C^{x_{i}}- \\
& (C-1) \sum_{i=1}^{n} \frac{B x_{i} C^{x^{-1}}}{A+B C^{x_{i}}}-\frac{B(C-1)}{C \ln ^{2} C} \sum_{i=1}^{n}\left(C^{x_{i}}-1\right) .
\end{aligned}
$$

The maximum estimation for parameter $A, B$ and $C$ will be obtained by solve the first partial derivative equation (14) respect to $A, B$ and $C$ :

$$
\begin{aligned}
& \frac{\partial \ln (L(A, B, C))}{\partial A}=A \sum_{i=1}^{n} \frac{1}{\left(A+B C^{x_{i}}\right)^{2}}+B \sum_{i=1}^{n} \frac{C^{x_{i}}}{\left(A+B C^{\left.x_{i}\right)^{2}}\right.}+(C-1) \sum_{i=1}^{n} \frac{B x_{i} C^{x_{i}-1}}{\left(A+B C^{\left.x_{i}\right)^{2}}\right.} \\
\frac{\partial \ln (L(A, B, C))}{\partial B}= & A \sum_{i=1}^{n} \frac{C^{x_{i}}}{\left(A+B C^{x_{i}}\right)^{2}}+B \sum_{i=1}^{n} \frac{C^{2 x_{i}}}{\left(A+B C^{x_{i}}\right)^{2}}+\frac{C-1}{C \ln C} \sum_{i=1}^{n} x_{i} C^{x_{i}}-(C-1) \sum_{i=1}^{n} \frac{A x_{i} C^{x_{i}-1}}{\left(A+B C^{x_{i}}\right)^{2}}- \\
& \frac{C-1}{C \ln ^{2} C} \sum_{i=1}^{n}\left(C^{x_{i}}-1\right), \\
\frac{\partial \ln (L(A, B, C))}{\partial C}= & A \sum_{i=1}^{n} \frac{B x_{i} C^{x_{i}-1}}{\left(A+B C^{x_{i}}\right)^{2}}-B \sum_{i=1}^{n} \frac{A x_{i} C^{x_{i}-1}}{\left(A+B C^{x_{i}}\right)^{2}}+\frac{B(\ln C-C+1)}{C^{2} \ln ^{2} C} \sum_{i=1}^{n} x_{i} C^{x_{i}}+ \\
& \frac{B(C-1)}{C \ln C} \sum_{i=1}^{n} x_{i}^{2} C^{x_{i}-1}-(C-1) \sum_{i=1}^{n} \frac{B x_{i}\left(x_{i}-1\right) C^{x_{i}-2}\left(A+B C^{x_{i}}\right)-\left(B x_{i} C^{x_{i}-1}\right)^{2}}{\left(A+B C^{x_{i}}\right)^{2}} \\
- & \frac{B(\ln C-2 C+2)}{C^{2} \ln ^{3} C} \sum_{i=1}^{n}\left(C^{x_{i}}-1\right)-\frac{B(C-1)}{C \ln ^{2} C} \sum_{i=1}^{n} x_{i} C^{x_{i}-1} .
\end{aligned}
$$

Equation (11) - (12) and (15) - (17) can be solved analytically, therefore we will solve it numerically. The popular method is Newton-Raphson. This method is able to estimate the parameter from the nonlinear equation iteratively. Let $\theta$ be parameter from $f\left(x_{1}, x_{2}, \ldots, x_{n} ; \theta\right)$ then steps in the NewtonRaphson method [14] are:

1. Determine the initial value: $\theta^{0}$.

2. $\widehat{\theta}^{1}=\theta^{0}-\frac{G\left(\theta^{0}\right)}{H\left(\theta^{0}\right)}$, where $H\left(\theta^{0}\right)$ is a first differentiation of $f\left(x_{1}, x_{2}, \ldots, x_{n} ; \theta\right)$ on $\theta=\theta^{0}$ and $G\left(\theta^{0}\right)=f\left(x_{1}, x_{2}, \ldots, x_{n} ; \theta^{0}\right)$.

3. $\hat{\theta}^{t+1}=\theta^{t}-\frac{G\left(\theta^{t}\right)}{H\left(\theta^{t}\right)}$, let $H\left(\theta^{t}\right)=H^{t}$ and $G\left(\theta^{t}\right)=G^{t}$. Then $\hat{\theta}^{t+1}=\theta^{t}-\left(H^{t}\right)^{-1} G^{t}$.

4. Do the iteration until $\left|\hat{\theta}^{t+1}-\hat{\theta}^{t}\right|<\varepsilon$. 
This method can be extended to solve the non-linear equation system with more than one parameter. Let $\theta_{1}, \theta_{2}, \ldots, \theta_{p}$ be the estimated parameters then the iteration will be:

$$
\hat{\theta}^{t+1}=\theta^{t}-\left(H^{t}\right)^{-1} G^{t}
$$

where $\hat{\theta}^{t+1}$ and $\theta^{t}$ is a vector.

Based on the previous research, the Newton-Raphson method succeeds to solve equation (11) (12) numerically but not succeed in solving equation (15) - (17). Therefore, we need another numerical method i.e. Broyden Method. The Broyden method is extended from the Secant method [15]. This method is used to solve non-linear equation systems. Let the non-linear equation system is $\boldsymbol{F}(\boldsymbol{x})=0$ with the initial approach $\boldsymbol{x}^{(0)}=\left(x_{1}, x_{2}, \ldots, x_{n}\right)^{t}$. The algorithm of the Broyden method is Step 1:
a. Form the Jacobian matrix $\boldsymbol{J}(\boldsymbol{x})$, where $\boldsymbol{J}(\boldsymbol{x})_{j, k}$
a column,
b. Substitute $\boldsymbol{x}^{(0)}$ into $\boldsymbol{F}(\boldsymbol{x})=0$ to find $\boldsymbol{F}\left(\boldsymbol{x}^{(0)}\right)$,
c. Substitute $\boldsymbol{x}^{(0)}$ into $\boldsymbol{J}(\boldsymbol{x})$ to find $\boldsymbol{J}_{\mathbf{0}}=\boldsymbol{J}\left(x_{1}^{(0)}, x_{2}^{(0)}, \ldots, x_{n}^{(0)}\right)$,
d. Find $\boldsymbol{J}_{\mathbf{0}}^{-\mathbf{1}}$, the inverse of $\boldsymbol{J}_{\mathbf{0}}$,
e. $\boldsymbol{x}^{(1)}=\boldsymbol{x}^{(0)}-\boldsymbol{J}_{\mathbf{0}}^{-1} \boldsymbol{F}\left(\boldsymbol{x}^{(0)}\right)$.

Step 2: Substitute $\boldsymbol{x}^{(i)}$ into $\boldsymbol{F}(\boldsymbol{x})=0, i=1,2, \ldots$ to find $\boldsymbol{F}\left(\boldsymbol{x}^{(i)}\right)$.

Step 3: Calculate $\boldsymbol{y}_{\boldsymbol{i}}=\boldsymbol{F}\left(\boldsymbol{x}^{(i)}\right)-\boldsymbol{F}\left(\boldsymbol{x}^{(i-1)}\right), \boldsymbol{s}_{\boldsymbol{i}}=\boldsymbol{x}^{(i)}-\boldsymbol{x}^{(i-1)}, \boldsymbol{s}_{i}-\boldsymbol{J}_{i-1}{ }^{-1} \boldsymbol{y}_{i}$, and $\boldsymbol{s}_{\boldsymbol{i}}{ }^{\boldsymbol{t}} \boldsymbol{J}_{i-1}{ }^{-1}$.

Sept 4: Calculate $\boldsymbol{J}_{i}^{-1}=\boldsymbol{J}_{i-1}{ }^{-1}+\frac{\left(\boldsymbol{s}_{i}-\boldsymbol{J}_{i-1}^{-1} \boldsymbol{y}_{i}\right) \boldsymbol{s}_{\boldsymbol{i}}{ }^{t} \boldsymbol{J}_{i-1}^{-1}}{\boldsymbol{s}_{\boldsymbol{i}}{ }^{-1} \boldsymbol{J}_{i-1}{ }^{-1} \boldsymbol{y}_{\boldsymbol{i}}}$

Step 5: Calculate $\boldsymbol{x}^{(i+1)}=\boldsymbol{x}^{(i)}-\boldsymbol{J}_{i}^{-1} \boldsymbol{F}\left(\boldsymbol{x}^{(i)}\right)$

Step 6: If $\left\|\boldsymbol{x}^{(i+1)}-\boldsymbol{x}^{(i)}\right\|<\varepsilon$ then the iteration finish and the best solution is $\boldsymbol{x}^{(i+1)}$. If not, the iteration back to Step 2 .

The fit of the 2011 TMI to Gompertz's law will be evaluated based on the fitness of the ${ }_{t} p_{x}$ in the 2011 TMI and the ${ }_{t} p_{x}$ in Gompertz's law in equation (3) using Average Relative Error (ARE) [16], i.e.:

$$
A R E=\frac{\sum_{i=1}^{n}\left|e_{i}-o_{i}\right|}{\sum_{i=1}^{n} o_{i}}
$$

where $e_{i}$ is the $p_{x}$ in the Gompertz's or the Makeham's law and $o_{i}$ is the $p_{x}$ in the 2011 TMI. After we get the best fitness for the 2011 TMI, we will evaluate the $p_{x}$ based on the age interval using Mean Absolute Percentage Error (MAPE):

$$
M A P E=\frac{100 \%}{n} \sum_{t=1}^{n}\left|\frac{A_{t}-F_{t}}{A_{t}}\right|,
$$

where $A_{t}$ is $p_{x}$ in the 2011 TMI and $F_{t}$ is $p_{x}$ on the best law. 
Fit of the 2011 Indonesian Mortality Table 2011 to Gompertz's and Makeham's Law using Maximum...

\section{RESULT AND DISCUSSION}

For the Gompertz's law, based on equation (11) - (12), the iterative equation to estimate parameter $\mathrm{B}$ and $\mathrm{C}$ numerically using the Newton-Raphson method is

$$
\left(\begin{array}{l}
B_{k+1} \\
C_{k+1}
\end{array}\right)=\left(\begin{array}{l}
\beta_{k} \\
\bigotimes_{k}
\end{array}\right)-\left(\begin{array}{ll}
\frac{\partial^{2} \ln L}{\partial B^{2}} & \frac{\partial^{2} \ln L}{\partial B \partial C} \\
\frac{\partial^{2} \ln L}{\partial C \partial B} & \frac{\partial^{2} \ln L}{\partial C^{2}}
\end{array}\right)^{-1}\left(\begin{array}{l}
\frac{\partial \ln L}{\partial B} \\
\frac{\partial \ln L}{\partial C}
\end{array}\right), \quad k=0,1,2, \ldots, n
$$

Initial value for $C$ is 1.09 [17]. The tolerance equation is $\sqrt{\left(B_{k+1}-B_{k}\right)^{2}+\left(C_{k+1}-C_{k}\right)^{2}} \leq \varepsilon$ and the estimation valid if the constraint for $B>0$ and $C>1$ are satisfied. We use $\varepsilon=10^{-4}$. The result shows that parameter $B$ converges to 0.005749 and $C$ converges to 1.024738 . We substitute the parameter $B$ and $C$ to equation (1) - (2). Figure 1 shows the force of mortality (left) and pdf (right).
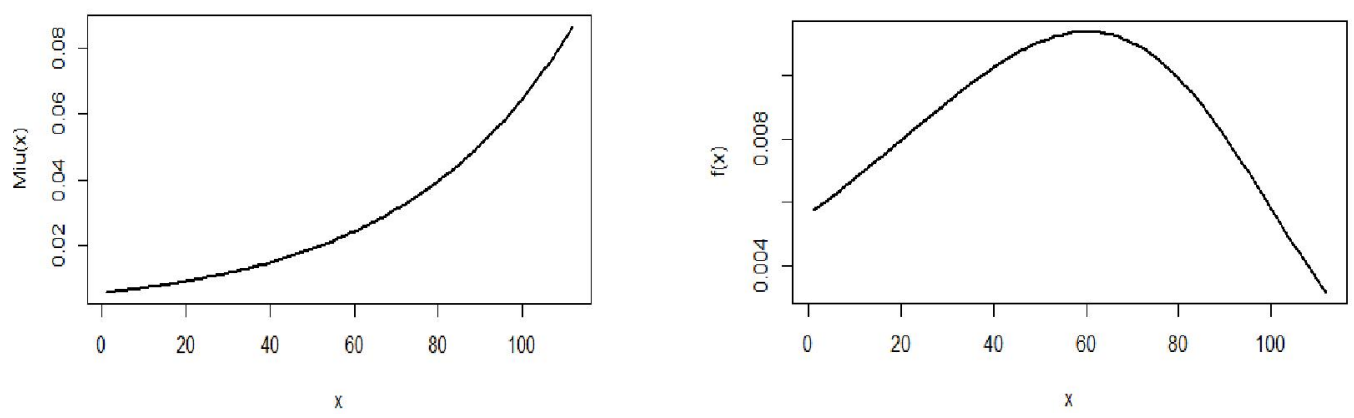

Figure 1. The plot of the force of mortality (left) and pdf (right) for Gompertz's law.

For Makeham's law, based on equation (15) - (17), the Jacobian matrix for the Broyden method is

$$
J=\left(\begin{array}{lll}
\frac{\partial^{2} \ln L}{\partial A^{2}} & \frac{\partial^{2} \ln L}{\partial A \partial B} & \frac{\partial^{2} \ln L}{\partial A \partial C} \\
\frac{\partial^{2} \ln L}{\partial B \partial A} & \frac{\partial^{2} \ln L}{\partial B^{2}} & \frac{\partial^{2} \ln L}{\partial B \partial C} \\
\frac{\partial^{2} \ln L}{\partial C \partial A} & \frac{\partial^{2} \ln L}{\partial C \partial B} & \frac{\partial^{2} \ln L}{\partial C^{2}}
\end{array}\right)
$$

Based on [12], $C_{0}=[1.1075 ; 1.115]$. To satisfied equation $(7)-(9)$, we use $A_{0}=0.0015, B_{0}=$ $0.0009, C_{0}=1.11341$ and $\varepsilon=10^{-4}$. The tolerance equation is $\sqrt{\left(A_{k+1}-A_{k}\right)^{2}+\left(B_{k+1}-B_{k}\right)^{2}+\left(C_{k+1}-C_{k}\right)^{2}} \leq \varepsilon$. The estimation is valid if the constrains $B>0$, $C>1$, dan $A>-B$ are satisfied. We obtain the parameter estimation $A$ converges to $0.00300344, B$ converges to 0.0002716465 , and $C$ converges to 1.113395 . We substitute these estimations to equation (4) - (5) and we obtain the plot of force of mortality and the pdf in Figure 2.

Based on the estimation parameter for Gompertz's and Makeham's law, we can see the fitness of $p_{x}$ in the 2011 TMI to $p_{x}$ for these two models in Figure 3 for the men (left) and women (right). The average relative error of the fitness $p_{x}$ in the 2011 TMI for men and women to Gompertz's and Makeham's law (in \%) will be shown in Table 1. 

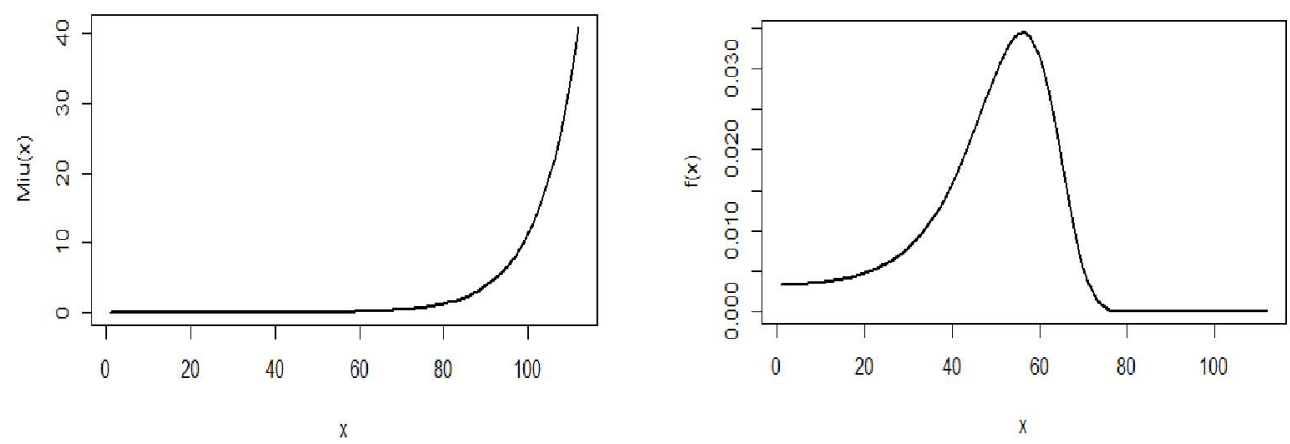

Figure 2. The plot of the force of mortality (left) and pdf (right) for Makeham's law.
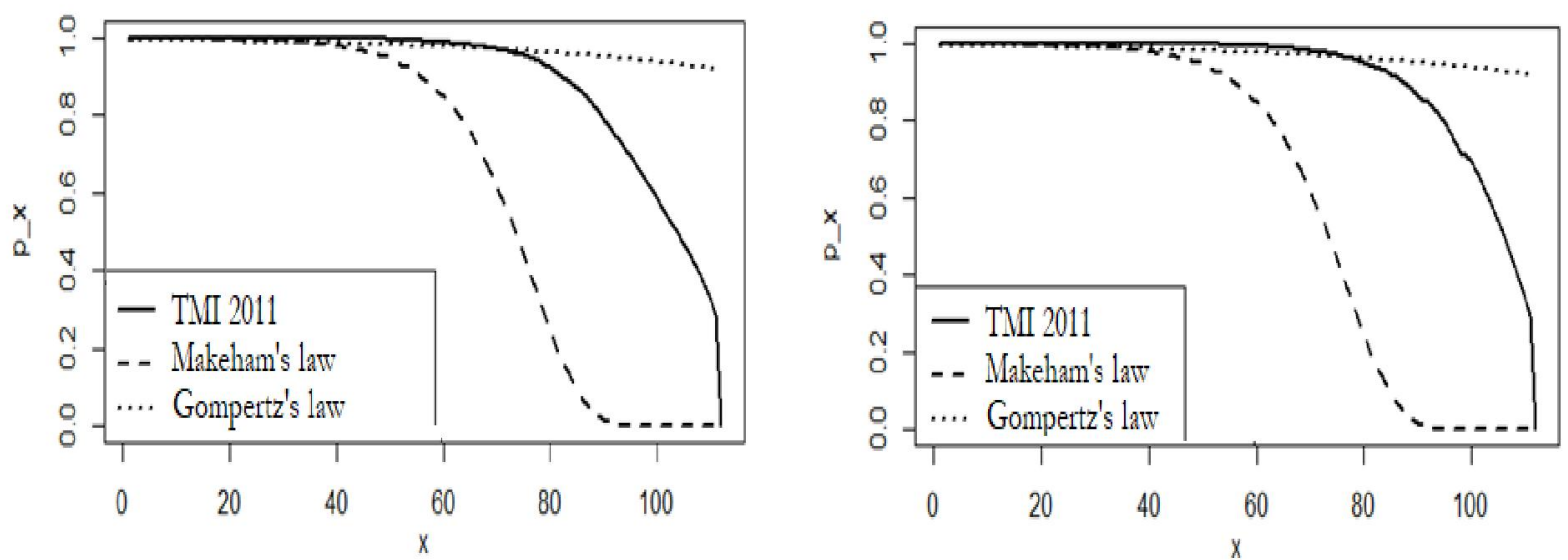

Figure 3. The $p_{x}$ in the 2011 TMI for the men (left) and women (right) compare to $p_{x}$ in Gompertz's and Makeham's law for age 0 to 110 years old.

Table 1. The Average Relative Error of the fitness of $\boldsymbol{p}_{\boldsymbol{x}}$ in the 2011 TMI for men and women to Gompertz's and Makeham's law.

\begin{tabular}{ccc}
\hline \multirow{2}{*}{ The 2011 TMI } & \multicolumn{2}{c}{$p_{x}$} \\
\cline { 2 - 3 } & Gompertz's & Makeham's \\
\hline Men & $10.79138 \%$ & $28.69648 \%$ \\
\hline Women & $8.482467 \%$ & $30.3038768 \%$ \\
\hline
\end{tabular}

Table 1 shows that the fitness of $p_{x}$ in the 2011 TMI for men and women are close to Gompertz's. However, this fitness is rather far if the age of more than 60 years old. Therefore, we should find the age interval when Gompertz's law is the best fit for the 2011 TMI. Table 2 shows the MAPE for the fitness of $p_{x}$ in the 2011 TMI for men and women for some age interval. From Table 2, we can see that the MAPE of fitness of $p_{x}$ in the 2011 TMI for the men to Gompertz's law lower than $1 \%$ for the age interval are $0-10$ years old, $10-20$ years old, $20-30$ years old, and $60-70$ years old. However, for women, the age interval are $0-10$ years old, $10-20$ years old, and $70-80$ years old. 
Fit of the 2011 Indonesian Mortality Table 2011 to Gompertz's and Makeham's Law using Maximum...

Tabel 2. The MAPE of fitness of $\boldsymbol{p}_{\boldsymbol{x}}$ in the 2011 TMI for men and women to Gompertz's law.

\begin{tabular}{cccc}
\hline \multirow{2}{*}{ No } & Age & \multicolumn{2}{c}{ MAPE of $p_{x}$ (in $\left.\%\right)$} \\
\cline { 3 - 4 } & interval & Men & Women \\
\hline 1 & $0-10$ & 0.5868 & 0.5941 \\
\hline 2 & $10-20$ & 0.8072 & 0.8133 \\
\hline 3 & $20-30$ & 0.9969 & 1.0293 \\
\hline 4 & $30-40$ & 1.2636 & 1.2890 \\
\hline 5 & $40-50$ & 1.4358 & 1.5356 \\
\hline 6 & $50-60$ & 1.2589 & 1.6206 \\
\hline 7 & $60-70$ & 0.6547 & 1.4384 \\
\hline 8 & $70-80$ & 1.9886 & 0.6539 \\
\hline 9 & $80-90$ & 12.4243 & 5.3904 \\
\hline 10 & $90-100$ & 41.6938 & 23.6484 \\
\hline 11 & $100-110$ & 120.7968 & 99.2902 \\
\hline
\end{tabular}

\section{CONCLUSION}

This research is succeeded to estimate the parameter of Gompertz's and Makeham's law using the Maximum Likelihood Estimation method. However, the estimation can't do analytically, therefore we use the Newton-Raphson method to estimate the parameters in Gompertz's law and the Broyden method to estimate the parameters in Makeham's law. The result shows that parameter $B$ converges to 0.005749 and $C$ converges to 1.024738 for Gompertz's law and the parameter estimation A converges to 0.00300344 , B converges to 0.0002716465 , and C converges to 1.113395 for Makeham's law. Besides, based on the value of the Average Relative Error, the $p_{x}$ in the 2011 TMI for men and women are appropriate to Gompertz's law for the age's interval 0 - 10 years old, 10 - 20 years old, 20 -30 years old, and $60-70$ years old for men, and the age's interval $0-10$ years old, $10-20$ years old, and $70-80$ years old for women.

\section{REFERENCES}

[1] N. Bowers, JR., H. Gerber, D. Jones dan C. Nesbitt, Actuarial Mathematics, Illinois: The Society of Actuaries, 1997.

[2] J. Cohen, C. Bohk-Ewald dan R. Rau, "Gompertz, Makeham, and Siler models explain'Taylor's law in human mortality data," Demographic Research, vol. 38, no. 29, pp. 773-842, 2018.

[3] T. B. L. Kirkwood, "Deciphering death : a commentary on Gompertz (1825) 'On The Nature of The Function Expressive of The Law of Human Mortality, and on A New Mode of Determining The Value of Life Contingencies'," Philosophical Transactions Of The Royal Society B, vol. 370, no. 1666, 2015.

[4] E. L. Turner dan J. A. Hanley, "Cultural imagery and Statistical Models of The Force of Mortality : Addison, Gompertz, and Pearson," Journal of The Royal Statistical Society, vol. 173, no. 3, pp. 483-500, 2010.

[5] W. M. Makeham, "On the Law of Mortality and the Construction of Annuity Tables," Journal Of The Institute Of Actuaries, vol. 8, no. 6, pp. 301-310, 1860.

[6] C. W. Jordan, Society of Actuaries' Textbook on Life Contingencies, Chicago: The Society of Actuaries, 1991. 
[7] S. J. Olshansky dan B. A. Carnes, "Ever Since Gompertz," Demography, vol. 34, no. 1, pp. 1-15, 1997.

[8] T. H. Tai dan A. Noymer, "Models For Estimating Empirical Gompertz Mortality : With An Application To Evolution Of Gompertzian Slope," The Society Of Population Ecology, vol. 60, no. 1-2, pp. 171-184, 2018.

[9] M. L. Garg, B. R. Rao dan C. K. Redmond, "Maximum Likelihood Estimation Of The Parameters Of The Gompertz Survival Function," Journal Of The Royal Statistical Society Series C, vol. 19, no. 2, pp. 152-159, 1970.

[10] A. Lenart, "The Moments of The Gompertz Distribution and Maximum Likelihood Estimation of Its Parameters," Scandinavian Actuarial Journal, vol. 2014, no. 3, pp. 255-277, 2014.

[11] X. Feng, G. He dan Abdurishit, "Estimation Of Parameters Of The Makeham Distribution Using The Least Squares Method," Mathematics and Computers in Simulation, vol. 77, no. 1, pp. 3444, 2008.

[12] V. Huang dan F. Kristiani, "Analisis Kesesuaian Hukum Mortalita Gompertz dan Makeham Terhadap Tabel Mortalita Amerika Serikat dan Indonesia," Prosiding Seminar Nasional Matematika Unpar, vol. 7, no. 2, pp. 63-69, 2012.

[13] R. V. Hogg dan A. T. Craig, Intoduction to Mathematical Statistics, New Jersey: Prentice-Hall, 2013.

[14] A. Ben-Israel, “A Newton-Rhapson Method for the Solution of systems of Equations," Journal of Mathematical Analysis and Applications, vol. 15, pp. 243-252, 1996.

[15] C. G. Broyden, "A Class of Methods for Solving Nonlinear Simultaneous Equations," Mathematics of Computation, vol. 19, no. 92, pp. 577-593, 1965.

[16] S. Zhou, X. S. Qian dan P. C. Yi, Probability Theory and Mathematical Statistics, Zhejiang: Higher Education Press, 1988.

[17] P. Andreopoulos, B. G. Fragkiskos, A. Tragaki dan A. Rovolis, "Mortality modeling using probability distributions," Communications in Statistics - Theory and Methods, vol. 48, no. 1, pp. 127$140,2018$. 